\title{
A Subsystem Designed for Mobile Business Management - SELCOM - Value Chain
}

\author{
Mihaela Tomescu ${ }^{1}$, Daniel Savu ${ }^{1}$, Eugen Pop $^{2}$ \\ ${ }^{1}$ National Institute for Research and Development in Informatics - ICI Bucharest \\ mtomescu@ici.ro,dsavu@ici.ro \\ ${ }^{2}$ Research Development, \\ Engineering and Manufacturing for Automation Equipment and Systems - S.C. IPA S.A \\ epop@ipa.ro
}

\begin{abstract}
The article presents the SELCOM - Value Chain subsystem designed for mobile business management which is a part of the Integrated ebusiness platform dedicated to the provision of services through $3 \mathrm{G}$ mobile communication networks - SELCOM. The SELCOM - Value Chain subsystem is included in the SELCOM platform and assures the assistance of the chain of processes that represent values of a business entity based on the usage of Information and Communication Technologies (ITC). SELCOM platform is a hardware and software integrated platform based on a client-server architecture dedicated to the provision of ebusiness services through $3 \mathrm{G}$ mobile communication networks. Significant features of $3 \mathrm{G}$ systems are that they support much higher data transmission rates and offer increased capacity, which makes them suitable for high-speed data applications as well as for the traditional voice calls.
\end{abstract}

Keywords: Value chain management for mobile business, ebusiness services, 3G mobile communication networks, dynamic modelling.

\section{Introduction}

International Mobile Telecommunications2000 (IMT-2000), better known as 3G or 3rd Generation, is a generation of standards for mobile phones and mobile telecommunications services meeting the technical specifications established by the International Telecommunication Union (ITU) [1].

$3 \mathrm{G}$ mobile telephone networks are the latest stage in the development of wireless communications technology [3]. Significant features of $3 \mathrm{G}$ systems are that they support much higher data transmission rates and offer increased capacity, which makes them suitable for high-speed data applications as well as for the traditional voice calls. These systems are designed to process data; the voice signals are converted to digital data, fact that allows that speech to be dealt with in much the same way as any other form of data [3-4].

The benefits of higher data rates and greater bandwidth mean that $3 \mathrm{G}$ mobile phones can offer to subscribers a wide range of data services, such as mobile Internet access and multimedia applications. A $3 \mathrm{G}$ handset provides many new features and the possibilities for new services are almost limitless, including many popular applications such as TV streaming, multimedia, videoconferencing, Web browsing, e-mail, paging, fax, and navigational maps.
SELCOM platform is developed during the project "Integrated ebusiness platform dedicated to the provision of services through 3G mobile communication networks SELCOM". The main objective of the project is to develop a hardware and software integrated platform based on a client-server architecture dedicated to the provision of ebusiness services through $3 \mathrm{G}$ mobile communication networks [5].

SELCOM platform provides ebusiness services in the ecommerce and financial transactions areas and it allows the integration of these ebusiness services with basic services for the localisation of users and clients in the $3 \mathrm{G}$ mobile communication network [6]. Through the $3 \mathrm{G}$ mobile communication terminals and networks, the client accesses and uses the electronic service benefiting of mobility and a low price for the data traffic.

The software framework is configurable depending on the needs of the business entities because it allows access to databases, interconnection for the purpose of providing electronic content, Web services etc. The complexity of functional, hardware and software architecture confers to the SELCOM platform an integrated and open feature.

The hardware structure of the integrated platform is formed by the server of the 
business entity and $3 \mathrm{G}$ mobile terminals of the clients and the potential users. The software server application resides on the server of the business entity and connects to Internet through a cabled connection and software client application resides on the mobile terminal of the user of the electronic service. The server hosts ebusiness applications for electronic commerce and financial transactions. The integrated structure of the platform enables users to access services based on location of the clients in $3 \mathrm{G}$ mobile telephone networks.

The software server application is implemented as a portal and offers software modules, functions and resources to the business entity for the development and provision of electronic services.

The software client applications are designed to be installed on different $3 \mathrm{G}$ mobile terminals, smartphones and Personal Digital Assistants (PDA) with operating systems as Symbian, Windows for Mobile, etc., used by clients to access the electronic services. The client application performs data traffic in $3 \mathrm{G}$ networks and also accesses services and protocols such as Global Package Radio Service (GPRS) [7], Enhanced Data GSM Environment (EDGE), Wireless Application Protocol (WAP), Global System for Mobile Communications (GSM), Short Message Service (SMS), Multimedia Messaging Service (MMS), e-mail, Wi-Fi.

The article presents the SELCOM - Value Chain subsystem designed for mobile business management which is included in the SELCOM platform and provides assistance to the chain of processes that represent valuable assets for an entity which makes use of Information and Communication Technologies (ITC).

\section{SELCOM - Value Chain Subsystem Main Characteristics}

The SELCOM - Value Chain subsystem is designed for business entities that manufacture products using a technological flow chart. The subsystem is focused on the technological and commercial processes and on the interactions between them.
The subsystem transforms data in information and knowledge that are used within the business processes in activities as planning and forecasting. Thus, data gathered from different sources are consolidated, and processes become more efficient as result of successive evaluations based on data query and analyses.

The subsystem allows the business entities to efficiently use their own resources.

The analyses performed in real time permit identification and exclusion of issues before they aggravate.

The forecasting is characterised through a high degree predictability offering thus adequate answers to "what-if" scenarios.

The SELCOM - Value Chain subsystem integrates the processes specific to a business entity through its components of Customer Relationship Management (CRM) and Enterprise Resource Planning (ERP) and implements concepts of Business Intelligence (BI) [8] and Business Performance Management (BPM) [9-10].

The products manufactured by a business entity have been structured in two main categories: products and intermediary products.

Each type of product is manufactured within a technological chain which has well-defined specific characteristics. Every technological chain is based on a manufacturing technology which includes the following:

- Raw materials;

- Auxiliary materials;

- Performed operations;

- Equipments;

- Human resources.

Each operation is characterized by duration. Same operation can be found in more than one technological chain, but specific characteristics allow making the differentiation between them.

Figure 1 depicts the value chain of the subsystem by emphasizing the chaining in time and the functional dependencies between components. 


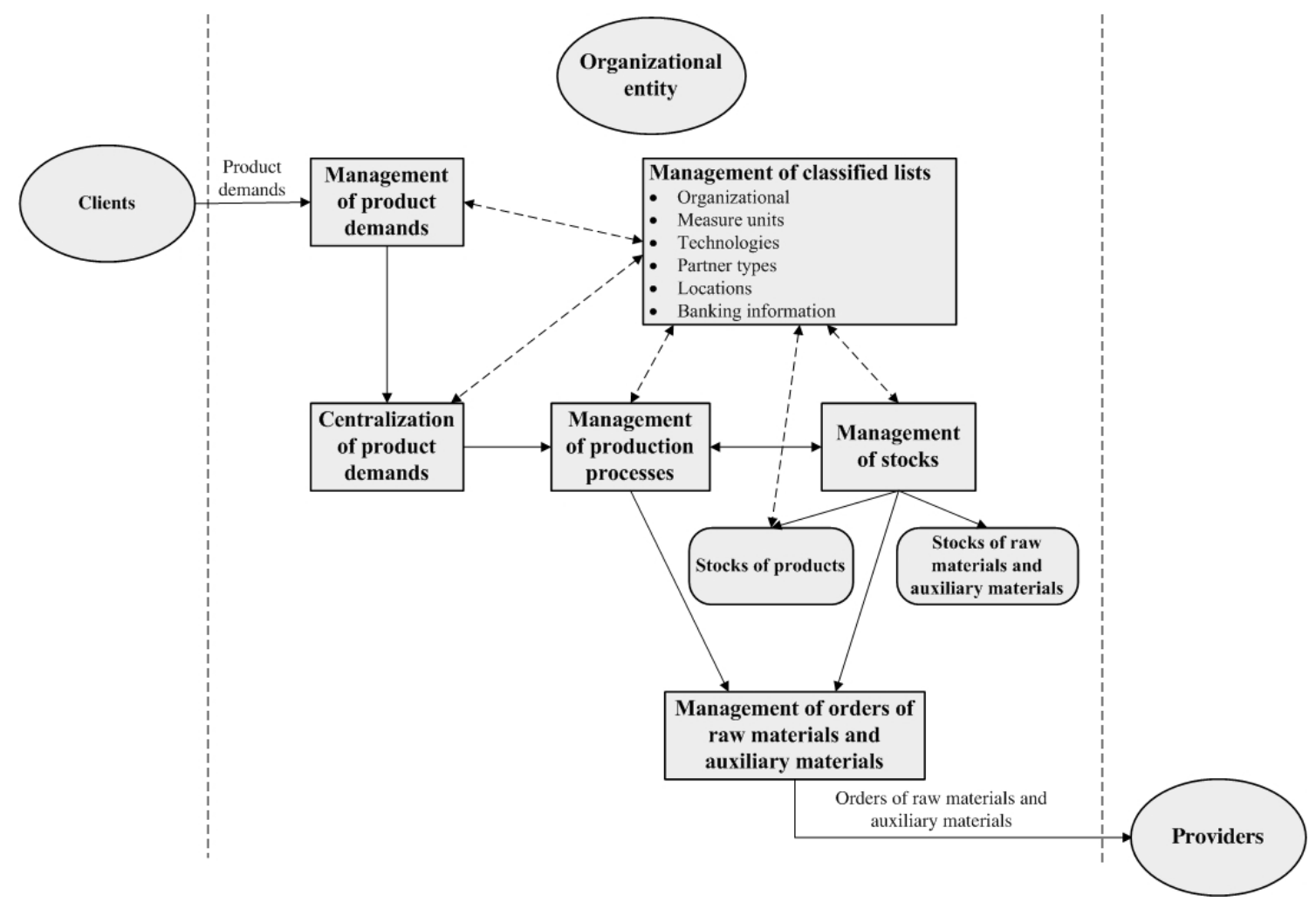

Figure 1. The subsystem value chain

\section{Subsystem Architecture}

The SELCOM - Value Chain subsystem is structured on three levels. Each level contains components. Each component of the mobile business management includes: an integrated set of relatively homogeneous activities that have a specific goal, well-defined actors and a clear mission. The levels of the subsystem are the following:

- Classified list;

- Functional components;

- Administration.

\section{Classified list level}

The Classified list level includes the Classified list management component.

\section{Functional components level}

Within the Functional components level there are included the following components:

- Management of the relationships with business partners;

- Management of product demands received from clients / product delivery documents;
- Management of raw material and auxiliary material demands sent to providers / raw material and auxiliary material delivery documents;

- Management of product, raw material and auxiliary material stocks;

- Management of production processes.

\section{Administration level}

The Administration level includes the Administration component.

The architecture of the SELCOM - Value Chain subsystem is presented in Figure 2. There are emphasized the levels, the components and the information interactions between them. 


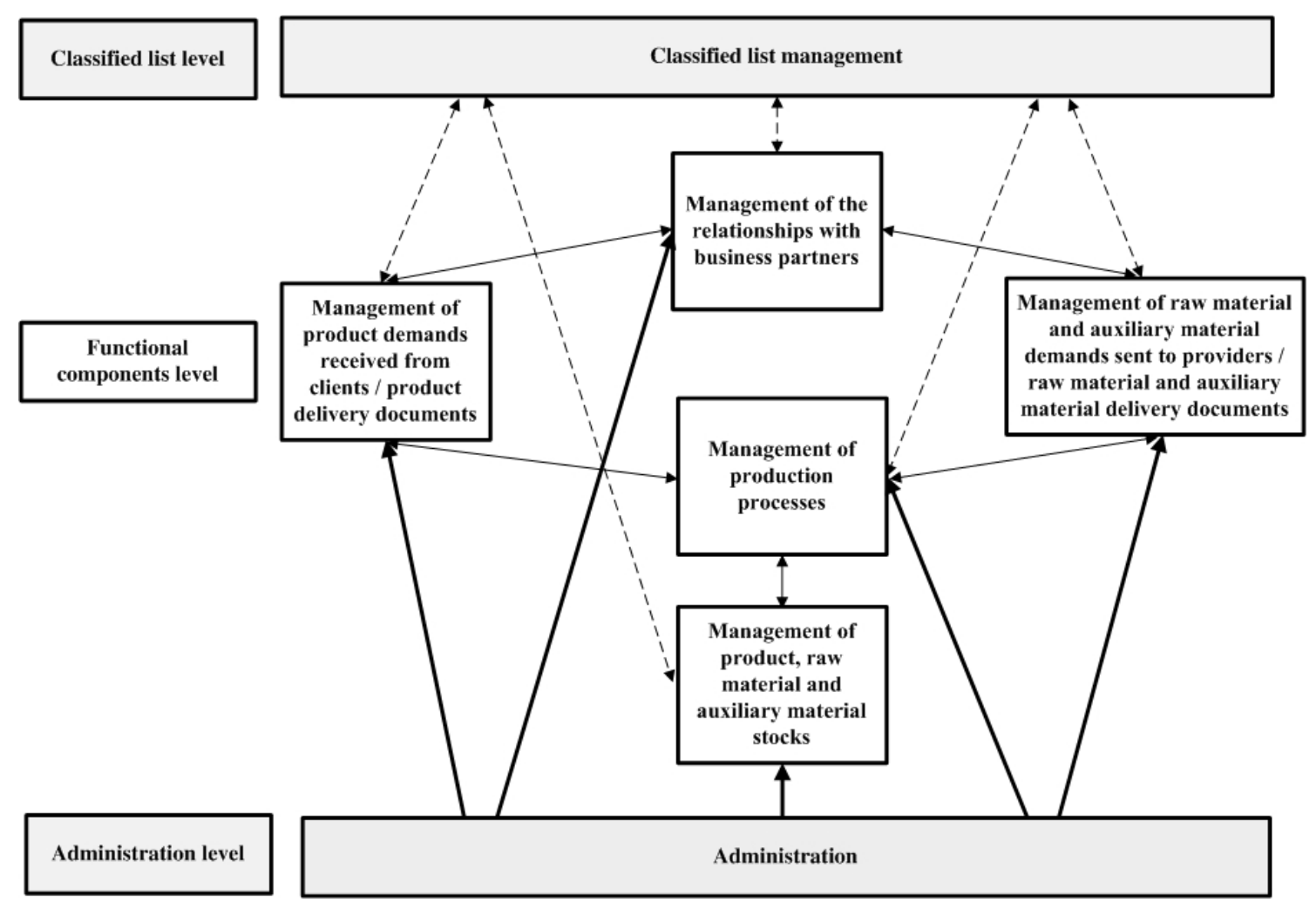

Figure 2. The subsystem architecture

\section{Subsystem Functions}

The subsystem designed for the value-chain management for mobile business provides a series of functions presented as follows.

\section{Management of clients}

The structures of data managed through this function pertain to the information regarding the client identification and presentation.

\section{Management of products}

The structures of data managed through this function pertain to the identification of products and the characteristics of the products.

\section{Management of product demands received from clients}

The types of considered product demands are:

- Fixed demands;

- Demands generated based on data with historical character regarding the received and sent demands;

- Pseudo-demands that will be registered directly by the subsystem users in conformance with the specific business politics.

\section{Management of providers}

The structures of data managed through this function pertain to the information regarding the provider identification and presentation.

\section{Management of raw materials}

The structures of data managed through this function pertain to the identification and characteristics of raw materials.

\section{Management of auxiliary materials}

The structures of data managed through this function pertain to the identification and characteristics of auxiliary materials.

\section{Management of raw material demands sent to providers}

The types of considered raw material demands are:

- Management of fixed raw material demands;

- Generation of acquisition demands with defined time margin. 
Management of auxiliary material demands sent to providers

The types of considered auxiliary material demands are:

- Management of fixed auxiliary material demands;

- Generation of acquisition demands with defined time margin.

\section{Management of stocks}

The structures of data managed through this function pertain to stocks of products, raw materials and auxiliary materials and point to quantities, minimal stock, validity/ keeping duration.

\section{Management of production processes}

The structures of data managed through this function pertain to identification of processes, their characteristics and mode of chaining in time of the processes considered at a given moment regarding a specified product.

\section{Offered Services}

The services offered by the SELCOM - Value Chain subsystem are the following:

- Classified List - allows the administration of the classified lists used by the subsystem;

- Partner Management - allows the administration of the relationships of a business entity with its business partners;

- Management of production - allows the administration of all the activities associated to the entire production process of a business entity starting from the product registration and ending with the product delivery;

- System administration service - the administration of the subsystem.

\section{Subsystem Facilities}

The SELCOM - Value Chain subsystem offers the following facilities:

- Provides data and tools to support the decision-making process;
- Offers business roadmaps and analysis which include data models;

- Helps the business entities to understand which processes control their activities and to predict the future impact of the decisions;

- Plays a key role in strategic planning manufacture process of the business entity;

- Includes customer profiling, client order registration and search;

- Is a real support for data gathering, storing, analyzing and access;

- Manages timely and accurate information providing support for decision, query and reporting, online analytical processing, statistical analysis, forecasting.

\section{Technologies and Standards Used in Subsystem Development}

The technologies used in the development of the SELCOM - Value Chain subsystem are:

- Framework: Microsoft.NET Framework 3.5 SP1;

- Ajax Library: Ajax Control Toolkit 3.0.529;

- Ajax Library: Visual Web GUI 6.3.0.12;

- MS Reporting Services 2008.

The standards used in the process of development of the SELCOM - Value Chain subsystem are:

- .NET CDN;

- Web Service REST.

\section{Technical Requirements for the Subsystem Usage}

The technical requirements for the usage of the SELCOM - Value Chain subsystem are:

For the server-side:

- Operating system: Windows Server 2003, Windows Server 2008;

- Database management system: SQL Server 2005, SQL Server 2008;

- Framework: Microsoft.NET Framework 3.5 SP1; 
- Library for Web report generation: SQL Report Viewer 2008.

For the client-side:

- Web browser: Internet Explorer, Firefox, Google Chrome.

\section{Elements of Innovation}

The innovation elements created in the project and implemented in the SELCOM - Value Chain subsystem are of two types, namely: functional innovation and technical innovation.

The functional innovation consists of dynamic modelling of technological processes in conformity with the on-going modification of product demands and considering the evolution of the production processes. The technological flow is automatically and dynamically built based on the situation of the raw and auxiliary material stocks existing at the planning moment through the creation of a chain of operations (characterised by inputs / outputs), so the inputs needed by an operation correspond with the outputs of its previous operation in the flow. In conformity with the available stocks, the technological flow for a certain product may vary from one planning to another. In the process of modelling and definition of manufacture technology planning scenarios, there are considered the quality parameters of raw materials and auxiliary materials in order to increase the product quality.

The technical innovation consists of creation of dynamic interfaces contextually chained based on Asynchronous JavaScript and XML (AJAX) [11-13] technology that allows asynchronous updating of areas from an active server page.

\section{Interfaces}

The SELCOM - Value Chain subsystem has user friendly interfaces being addressed to non-technical users. Some examples of interfaces are presented in Figures 3 - 4. In the design of the interfaces there have been considered the services offered to the users, the functions of these services and the processes support for the performance of the respective useful functions.

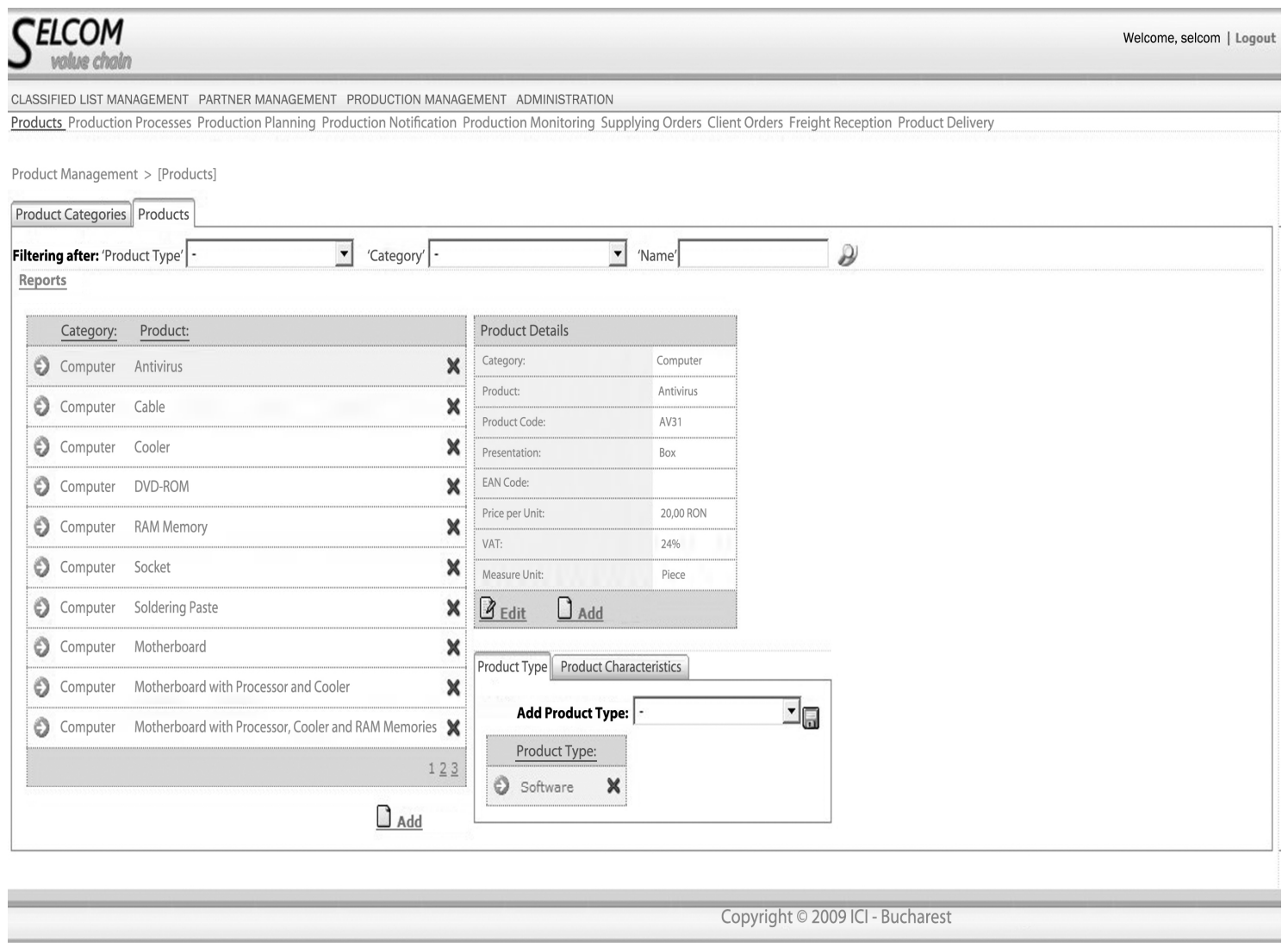

Figure 3. Management of the details regarding a product 


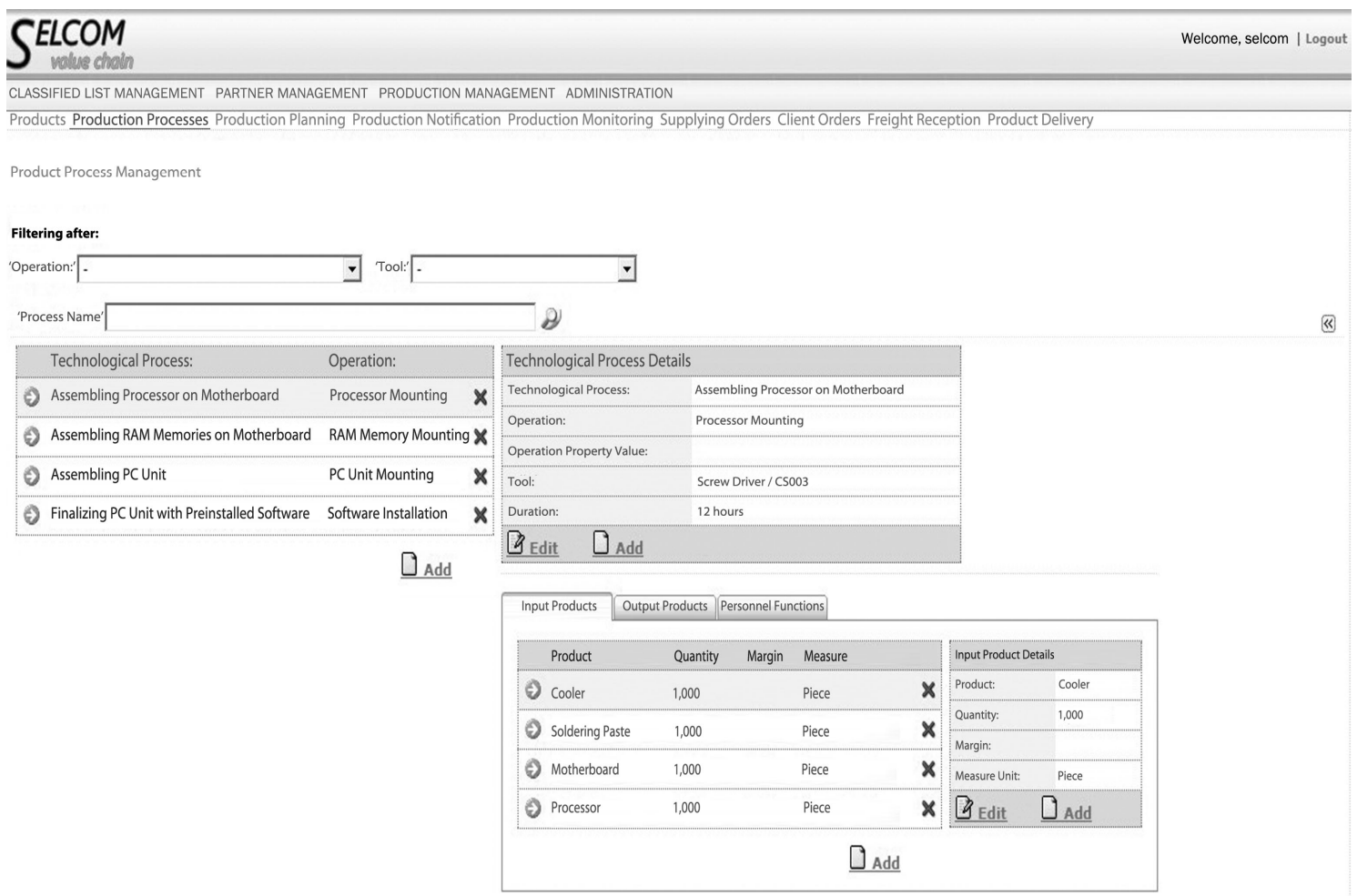

\section{Copyright $\odot 2009 \mathrm{ICI}$ - Bucharest}

Figure 4. Management of the details of a technological process

\section{Acknowledgment}

The SELCOM integrated ebusiness platform dedicated to the provision of services through 3G mobile communication networks platform is developed in a project within the National Plan for Research - Development and Innovation in Programme 4 "Partnerships in foreground areas" by a Romanian multidisciplinary consortium which includes a commercial society (S.C. IPA S.A.), two research institutions (S.C. ITC S.A. and ICI Bucharest) and a university (UPB). The SELCOM Value - Chain has been developed by National Institute for Research and Development in Informatics (ICI Bucharest).

The authors wish to acknowledge the technical support from the consortium of the project S.C. IPA S.A. and the funding support from Romanian Agency for Scientific Research.

\section{REFERENCES}

1. 3G, http://en.wikipedia.org/wiki/3G.

2. 3G - Third Generation networks, http://www.mobile-phone- directory.org/
Technology/3G_-_Third_Generation/.

3. Cellular Standards for the Third Generation, ITU, 1 December 2005. http://www.itu.int/osg/spu/imt-2000/technology. html\#Cellular\%20Standards\%20for\%20t he $\% 20$ Third $\% 20$ Generation.

4. Security for the Third Generation (3G) Mobile System, Network Systems \& Security Technologies. http://www.isrc.rhul.ac.uk/useca/OtherPu blications/3G_UMTS\%20Security.pdf.

5. Platformă integrată e-business pentru furnizarea de servicii prin rețele de comunicații mobile 3G - SELCOM, http://comunicatii.ipa.ro/selcom/index.html.

6. HRIN, G. R., L. E. ANGHEL, M. TOMESCU, D. SAVU, Mobile communication platform for business services - MOBACCES, Studies in Informatics and Control ISSN: $1220-$ 1766, Vol. 17, No. 3, 2008, pp. 253-258.

7. HALONEN, T., J. MELERO, J. ROMERO GARCIA, GSM, GPRS and EDGE Performance: Evolution Toward 3G/UMTS, May 13, 2002, p. 352 
8. Vodapalli, T. K., Critical Success Factors of BI Implementation, IT University of Copenhagen. http://mit.itu.dk/ucs/pb/download/BI\%20T hesis\%20Report-New.pdf?file_id=871821. 11 November 2009.

9. PUGNA, I. B., F. ALBESCU, D. BĂBEANU, The role of Business Intelligence in Business Performance Management,http://steconomice.uoradea .ro/anale/volume/2009/v4-managementand-marketing/210.pdf, 2009.

10. COKINS, G., Performance Management: Integrating Strategy Execution, Methodologies, Risk, and Analytics, ISBN 978-0-470-44998-1, 2009.
11. NORTON P., S. WILLIAM, Ghid de programare în Java, TEORA Publishing House, Bucharest, Romania, 1997.

12. BOIAN, F. M. Programarea distribuită în Internet, metode şi aplicații, Albastră Publishing House, Cluj-Napoca, Romania, 1997.

13. ANGHEL, T., Dezvoltarea aplicațiilor web folosind PHP şi AJAX, Edusoft Publishing House, 2008. 